\title{
Effect of Household Cooking Methods on the Viability of Bacillus Probiotics Supplemented in Cooked Sausage
}

\author{
Mojtaba Jafari ${ }^{1}$, Amir M. Mortazavian ${ }^{2 *}$, Hedayat Hosseini $^{2 *}$ \\ 1- Dept.of Food Science and Technology, Faculty of Industrial and Mechanical Engineering, Islamic Azad University, Qazvin Branch, Qazvin, Iran \\ 2- Dept.of Food Science and Technology, Faculty of Nutrition Sciences, National Nutrition and Food Technology Research Institute, Shahid Beheshti \\ University of Medical Sciences, Tehran, Iran
}

\section{A B S T R A C T}

Background and Objectives: The use of Bacillus probiotics is an interesting way for manufacturing healthier meat and meat products as functional foods and also a valuable solution for overcoming the constraints related to the stability of probiotic strains of Lactobacillus and Bifidobacterium during processing and storage of foods. This work is an attempt to investigate the influence of common household cooking methods on the viability of Bacillus coagulans and Bacillus subtilis as probiotic sporeformers inoculated into cooked sausages.

Materials and Methods: After preparation of the final suspensions of Bacillus coagulans ATCC 31284 and Bacillus subtilis var. Natto ATCC 15245 spores, they were supplemented in the sausage samples with different meat types and percentages. The inoculated cooked sausages were then submitted to common household cooking methods, i.e. boiling, microwaving, and deep fat frying. Enumeration of the studied spores was carried out on trypticase soy agar after exposure to a heat shock at $68^{\circ} \mathrm{C}$ for $20 \mathrm{~min}$. One-way analysis of variance (ANOVA) of SPSS-20 was used for statistical analysis of the data. A Taguchi $\mathrm{L}_{9}$ experimental design comprising 3 variables and 3 levels was performed using MINITAB-17 to determine main effects of the parameters of household cooking process.

Results: The results obtained in this study showed that boiling, followed by microwaving and deep fat frying, had the greatest viability and recovery of the studied spores supplemented in the cooked sausages, respectively $(P<0.05)$. Furthermore, results of the Taguchi experimental method revealed that the type of Bacillus probiotics, followed by the formulation of cooked sausages and the method of household cooking of cooked sausages had main effects on the concentrations of the spores examined, respectively.

Conclusions: The information provided here suggests that boiling as a common household cooking method retained maximum viability and recovery of the studied Bacillus probiotics supplemented in the cooked sausage samples. Besides, the type of spores was the principle parameter, which had a critical effect on the response (i.e. concentrations of the studied Bacillus probiotics).

Keywords: Bacillus probiotic, B. coagulans, B. subtilis, Cooked sausage, Household cooking method

\section{Introduction}

The development and consumption of probiotic food products is a growingly global consumer trend that has achieved a considerable remark in functional food market (1). Nonetheless, functional foods like food products containing probiotic microorganisms constitute an outstanding opportunity and a promising

market for the meat industry with regard to improving the quality and developing healthier meat and meat products (2, 3). According to an expert panel commissioned by FAO and WHO, probiotics are "live microorganisms, which when administered in adequate amounts, confer a health benefit on the host" 
$(4,5)$. Many different microorganisms have been considered as probiotics, mostly species of Lactobacillus and Bifidobacterium as traditional probiotic bacteria, and some species of sporeforming Bacillus genus as novel probiotic bacteria $(6,7)$. According to Ashraf and Shah (8) and Jayamanne and

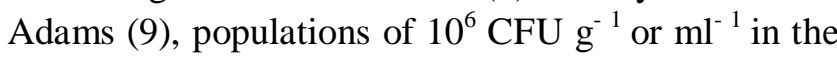
final product at the time of consumption, supposing a daily consumption of $100 \mathrm{~g}$ or $\mathrm{mL}$, are established as a minimum daily therapeutic dose of probiotic cultures in processed foods, reaching $10^{8} \mathrm{CFU}$, and hence, conferring health benefits to consumers.

The application of spores of Bacillus species as probiotic dietary supplements is expanding extensively and rather rapidly due to immune stimulation, antimicrobial activities, and competitive exclusion (10-12). Among the 100 known Bacillus spp., only a few strains of some species (including $B$. coagulans and B. subtilis var. Natto) have been used as probiotics for human consumption (13, 14). Considering their spore-forming nature, probiotic Bacillus strains possess improved viability and survivability as well as probiotic properties during the harsh manufacturing processes (like cooking), the storage of the product, and finally, passage through the gastrointestinal tract as compared to other probiotic bacterial strains $(6,15-18)$. In other words, sporeforming probiotic bacteria could be considered as a valuable solution for overcoming the limitations related to the stability of probiotic strains of Lactobacillus and Bifidobacterium during processing and storage of foods $(6,7,11,12,19)$. Apart from supporting probiotic microorganisms by clinical data to yield health benefits, this aspect is of great importance for factories and research centers interested in formulating products with probiotic microorganisms. Therefore, it seems that they represent an ideal choice for the development of functional cooked meat-based products, which constitute a very high proportion of the meat industry. On the other hand, the establishment of appropriate conditions for spore activation and recovery is highly important for proper assessment of the viability of probiotic cultures through the shelf life of food products and exposure to gastrointestinal conditions. Hence, heat shock and culture medium (in which spores are suspended) have a profound effect on the recovery and maximizing the germination rates of probiotic sporeforming bacteria (20-22).
Although thermal and cooking processing of meat and meat products seems not to cause reductions in the counts of bacterial spores, it may lead to sublethal injuries that may further reduce the resistance of spores in the gastrointestinal environment (23). Then the generation of this information is of major relevance for the development of probiotic foods considering that appropriate amounts of probiotic sporeforming bacteria can be added to the formulations to ensure health benefits. The household cooking practices being applied by the food handlers, either in homes or in fast food restaurants and catering centers, are generally based on personal preferences and convenience for handling and consuming foods (24). However, it appears that the most common methods of household cooking for cooked sausages are boiling, microwaving, and frying. Heating time, temperature, cooking method and, of course, meat product formulation are all important variables, which may influence on the viability and recovery of probiotic Bacillus in cooked sausages. Moreover, dielectric properties and thermal conductivity of foods like meat and meat products greatly affect the behavior of food during household cooking methods. It appears that thermal conductivity of foods relies largely on the amount and structuring of different components, especially water (25). In fact, the thermo-physical properties of the constituents of meat products (particularly meat as a main component) have an effect on the temperature profile and heating rate, and thereby the viability and recovery of the supplemented probiotic Bacillus spores (26). It is important to bear in mind that in conventional methods of home cooking including boiling and frying, energy is transferred to the material through convection, conduction, and radiation of heat from the surfaces of the material due to thermal gradients (26). On the contrary, microwave energy in cooking is delivered directly to materials through direct interaction of the electromagnetic field with the molecules of the target material (26). However, to our knowledge, the influence of household cooking methods on the viability and recovery of probiotic sporeformers in cooked food matrices has not yet been investigated. On the other hand, Taguchi method based on orthogonal arrays can be used to analyze a large number of variables with a few experimental trials (27). In fact, in contrast to other experimental design methods like full factorial, the Taguchi method as a simple and robust technique 
facilitates to identify the influence of process parameters and establish the relationship between variables and operational conditions, and significantly reduce the number of experimental arrays that may cause an increase in time and cost (28, 29). Accordingly, here, we aimed to evaluate the effect of different cooking methods, widely used in household processing (including boiling, microwaving, and frying), on the viability and recovery of probiotic Bacillus strains, i.e. B. coagulans ATCC 31284 and B. subtilis var. Natto ATCC 15245, which were inoculated into cooked sausages. In other words, this research, for the first time, attempts to determine the optimum home cooking procedure of cooked sausages that may result in the highest viability and recovery of the supplemented probiotic Bacillus strains. Finally, Taguchi experimental design with $\mathrm{L}_{9}$ orthogonal array was used to explore the effects of the type of spore probiotics, the formulation of cooked sausages, and the method of household cooking of cooked sausages and their priorities on the viability of the studied probiotic Bacillus strains.

\section{Materials and Methods}

Materials and chemical reagents: All the chemical and reagents used for the study were of analytical grade and purchased from Merck (Darmstadt, Germany).

Strains: Commercial probiotic sporeforming bacteria strains of Bacillus coagulans ATCC 31284 and Bacillus subtilis var. Natto ATCC 15245 were obtained from Natures Only, INC. (USA), and World Intellectual Resource Co. (Taiwan), respectively (21, 30, 31).

Preparation of spores: Evaluation of the purity of the studied strains and their preparation were conducted by the method described by Alebouyeh et al. (32). After intermittent steps of washing with chemical reagents (including $\mathrm{KCl} / \mathrm{NaCl}$, Tris- $\mathrm{HCl}$, SDS, Te buffer) and then sterile deionized water, followed by centrifugation $(12000 \times g, 15 \mathrm{~min})$, the final suspensions obtained were diluted in defined amounts of sterile deionized water. The concentration of spores per $\mathrm{mL}$ of each spore suspension was verified using Neubauer chamber, approved via plate count (32), following storage at $-70^{\circ} \mathrm{C}$ until analyzed.

Heat treatment procedure and culture medium: To have an accurate enumeration and the maximum recovery of the studied probiotic sporeforming bacteria, the influence of heat treatment (heat shock) condition and culture medium was also considered. According to the obtained results in our previous study, a heat shock at $68^{\circ} \mathrm{C}$ for $20 \mathrm{~min}$ and trypticase soy agar (TSA) medium yielded the highest viability and recovery of $B$. coagulans ATCC 31284 and $B$. subtilis var. Natto ATCC 15245 spores were chosen for this research (21).

\section{Cooked sausage manufacture}

Cooked sausage formulations: Cooked sausages were chosen as representative meat products because they account for a major part of the total consumption of processed meat products by the Iranian population. The cocktail sausages, containing 40, 55, and $70 \%$ meat contents, were manufactured in the pilot plant of Gooshtiran Factory of Meat Products, Tehran, Iran according to the industrial procedures. Frozen red meat packs $(15 \%$ fat $)$ were kept at $4^{\circ} \mathrm{C}$ for approximately $18 \mathrm{~h}$ for thawing. Fresh chicken meat (equal proportions of chicken breast and thigh) was used in the formulation of $55 \%$ cooked chicken sausage. The ingredients of the sausage mass and their relative proportions are given in Table 1.

Sausage preparation and inoculation with Bacillus probiotics: In practice, the control sausage sample (with no spore probiotic) was prepared as follows: the grounded minced meat (either red or white meat, depending upon the formulation) was transferred to a mini-cutter (Allen, K21 Ras 83132, Germany) with nitrite, sodium chloride $(\mathrm{NaCl})$, and polyphosphate at low speed to extract salt soluble proteins after comminution (during $3 \mathrm{~min}$, keeping the temperature below $12^{\circ} \mathrm{C}$ ). Then one-half of the proposed water in the formulation (as ground ice) was added, and mixed thoroughly in the cutter at high speed. Consequently after lowering the temperature of the mixture about 1$2{ }^{\circ} \mathrm{C}$, vegetable oil was added, and mixing was continued until reaching the temperature up to $8^{\circ} \mathrm{C}$. Afterwards, the remaining water (second half) and the rest of ingredients were incorporated, respectively, thoroughly mixed and chopped until the smooth distribution of all ingredients and the emulsion was obtained (batter) (for an additional $3 \mathrm{~min}$, approximately). A digital thermometer (Kane-May, KM330, Harlow, Germany) was applied for monitoring and verifying the temperature of the emulsion, which should be maintained below $12^{\circ} \mathrm{C}$ during the preparation of batter. 
Table 1. The basic formulation of cooked sausage batter prepared for this study.

\begin{tabular}{|c|c|c|c|}
\hline \multirow{2}{*}{ Ingredient } & \multicolumn{3}{|l|}{ Amount (\%) } \\
\hline & $40 \%$ cooked sausage & $55 \%$ cooked sausage & $70 \%$ cooked sausage \\
\hline Minced meat $^{1}$ & 40 & 55 & 70 \\
\hline Water (Ice) & 22 & 20 & 13 \\
\hline Vegetable oil & 19 & 10 & 4.5 \\
\hline Filler assortment $^{2}$ & 12 & 8 & 5.5 \\
\hline Frozen garlic & 1.8 & 1.8 & 1.8 \\
\hline Pasteurized whole egg & 2.0 & 1.5 & 1.5 \\
\hline Salt $(\mathrm{NaCl})$ & 1.6 & 2.0 & 2.0 \\
\hline Polyphosphate & 0.35 & 0.40 & 0.40 \\
\hline $\mathrm{NaNO}_{2}(10 \%$ water solution $)$ & 0.012 & 0.012 & 0.012 \\
\hline Ascorbate & 0.04 & 0.04 & 0.04 \\
\hline Sugar & 0.20 & 0.25 & 0.25 \\
\hline Spice assortment & 1 & 1 & 1 \\
\hline
\end{tabular}

${ }^{1}$ Beef used for cooked sausage manufacture was topside and shin beef (15\% fat). Chicken meat used for cooked chicken sausage production consisted of equal proportions of fresh chicken breast and thigh.

${ }^{2}$ It included wheat flour, wheat starch, gluten, and dried milk.

For production of inoculated formulations, spores of B. coagulans ATCC 31284 and B. subtilis var. Natto ATCC 15245 were individually inoculated at the start of cutter step after adding the first half of water and mixed at low speed for approximately 3 min in order to obtain a proper dispersion of the spores in the batter. The inoculum concentration of $B$. coagulans ATCC 31284 and B. subtilis var. Natto ATCC 15245 spores added to the cutter bowel was 12.88 and $12.96 \log \mathrm{CFU} / 10 \mathrm{~kg}$ (or 8.88 and $8.96 \mathrm{log}$ $\mathrm{CFU} / \mathrm{g}$ ), respectively. All batches after comminution/ chopping step were stuffed into artificial polyamide casings (24 mm diameter) (Arta, Tabriz, Iran) using a sausage stuffer (Handtman, Germany). The sausages were then cooked in a cooking cabinet with steam at $80 \pm 1^{\circ} \mathrm{C}$ (up to reaching the temperature of the geometric center to $73^{\circ} \mathrm{C}$ ) for approximately $60 \mathrm{~min}$. Subsequently, the cooked sausages were cooled down to about $25^{\circ} \mathrm{C}$ (room temperature) using cold water $\left(12^{\circ} \mathrm{C}\right)$ for approximately $8-10 \mathrm{~min}$. Next, the cooked sausages were stored at $4 \pm 1^{\circ} \mathrm{C}$ for 45 -day storage time and until analysis. Two independent replicates of the experiment were carried out. The samples were randomly taken from each sausage batch at the 15th day of refrigerated storage time according to ISO 3100-1 (33).

Household cooking methods: To investigate the influence of household cooking methods on the viability of B. coagulans ATCC 31284 and B. subtilis var. Natto ATCC 15245 spores in the cooked sausages with different meat percentages and types, three common cooking methods were used: boiling, microwaving, and deep fat frying. Preliminary household cooking trials were done by an informal testing panel consisting of 4 trained panelists to determine cooking times and temperatures required to achieve a constant degree of color and texture for the various home cooking methods examined. Boiling was performed in a water bath with sausages with casings completely submerged for $5 \mathrm{~min}$ at $95 \pm 5^{\circ} \mathrm{C}$. A domestic microwave oven (Samsung, model 9245, South Korea) with operating frequency of $2450 \mathrm{MHz}$ and an output power of $900 \mathrm{~W}$ was used for the microwave cooking experiment. For the samples to be microwaved, after aseptically removed from the casings, they were placed in a sterilized glass dish, and cooking was carried out for a period of $1 \mathrm{~min}$ at the maximal power setting $(900 \mathrm{~W})$. For the frying treatment, a deep fryer (Tefal, France) was set to $180 \pm 5^{\circ} \mathrm{C}$ for $10 \mathrm{~min}$ to reach the test temperature. The samples were aseptically removed from their respective casings, placed in a fryer pot containing hot frying oil, and deep fried at $180 \pm 5^{\circ} \mathrm{C}$ for $3 \mathrm{~min}$. After conducting the household cooking processes, the household-cooked sausages were cooled down for a few minutes at room temperature before being analyzed.

Enumeration of Bacillus probiotics in cooked sausage: The viable numbers of $B$. coagulans ATCC 31284 and B. subtilis var. Natto ATCC 15245 spores 
in the cooked sausages treated with different household cooking methods and also in the raw sausage sample (without household cooking) were determined by plate count on trypticase soy agar after exposure to a heat shock at $68^{\circ} \mathrm{C}$ for $20 \mathrm{~min}$. The plates were then incubated at $37^{\circ} \mathrm{C}$ for 2 days, the numbers of colonies grown were counted, and the results were expressed as CFU/g (21).

Experimental deign: The Taguchi fractional factorial experimental design provides the optimal selection of parametric values with an efficient and systematic manner for conducting experiments (34). In this work, we applied experimental design by the Taguchi method for obtaining which parameter/s of the household cooking process had the highest impact on the viability and recovery of the studied probiotic Bacillus strains supplemented in the cooked sausages. Consequently, three experimental parameters including the type of spore probiotic, the formulation of cooked sausages, and the method of household cooking of cooked sausages with three levels were selected as the independent variables, and their values are summarized in Table 2. Next, the matrix was designed with the appropriate orthogonal arrays for the selected parameters and their levels. Taguchi method provides many standard orthogonal arrays and corresponding linear graphs for this purpose (34). In the present study, $\mathrm{L}_{9}\left(3^{4}\right)$ orthogonal array (which indicated 9 experimental trials) with 3 columns and 9 rows was carried out to design experiment with selected parameters and levels. The experimental layout of $\mathrm{L}_{9}$ orthogonal array is shown in Table 3. In order to analyze the results, it used a statistical measure of performance called signal-to-noise $(\mathrm{S} / \mathrm{N})$ ratio. Usually, three types of $\mathrm{S} / \mathrm{N}$ ratio analysis are applicable: (1) smaller is better, (2) nominal is the best, and (3) higher is better (35). Since the objective of the present research work involves maximizing the viability of the studied probiotic Bacillus strains in cooked sausages, the $\mathrm{S} / \mathrm{N}$ ratio for the case of higher is better was selected. Minitab-17 Statistical Software (Minitab Inc., State College, PA, USA) was specifically used for design of experiment analysis.

Statistical analysis: The obtained results were expressed as means \pm standard deviations of two separate determinations. Colony-forming units (CFUs) in all experiments were converted into $\log _{10}$ values before statistical analysis. All data were treated by one-way analysis of variance (ANOVA). Comparison among the treatment averages was done by post hoc Duncan's multiple's range test at the significance level of $P<0.05$, i.e., at a confidence level of $95 \%$ (36). All of the statistical analyses were carried out using SPSS software, version 20 (SPSS Inc, Chicago, IL, USA).

Table 2. Parameters and their levels employed in the Taguchi method

\begin{tabular}{llll}
\hline Parameter & Level 1 & Level 2 & Level 3 \\
\hline Sausage formulation & $40 \%$ red meat & $55 \%$ red meat & $70 \%$ red meat \\
Spore probiotic & B. coagulans & B. subtilis & Control \\
Household cooking method $^{1}$ & BO & MW & DFF \\
\hline
\end{tabular}

${ }^{1}$ BO: boiling; MW: microwaving; DFF: deep fat frying.

Table 3. $\mathrm{L}_{9}\left(3^{4}\right)$ orthogonal array of Taguchi experimental design and response

\begin{tabular}{|c|c|c|c|c|}
\hline \multirow{2}{*}{ Experimental no. } & \multicolumn{4}{|c|}{ Parameters and their levels } \\
\hline & Sausage formulation & Spore probiotic & Household cooking method & $\begin{array}{c}\text { Viable spore count } \\
(\log \mathrm{CFU} / \mathrm{g})\end{array}$ \\
\hline 1 & 1 & 1 & 1 & 8.48 \\
\hline 2 & 1 & 2 & 2 & 7.92 \\
\hline 3 & 1 & 3 & 3 & 2.26 \\
\hline 4 & 2 & 1 & 2 & 8.78 \\
\hline 5 & 2 & 2 & 3 & 8.03 \\
\hline 6 & 2 & 3 & 1 & 2.63 \\
\hline 7 & 3 & 1 & 3 & 8.44 \\
\hline 8 & 3 & 2 & 1 & 8.76 \\
\hline 9 & 3 & 3 & 2 & 2.63 \\
\hline
\end{tabular}




\section{Results}

The results of viable counts of probiotic sporeforming bacteria inoculated into the cooked sausages after treating with household cooking methods are summarized in Table 4. As can be seen, there was no significant decline in the number of $B$. coagulans ATCC 31284 spores incorporated into the cooked sausages with $40 \%$ red meat after household cooking by boiling and microwaving $(P>0.05)$, whereas the highest viability of $B$. subtilis var. Natto ATCC 15245 spores inoculated into the cooked sausages with $40 \%$ red meat was obtained $(8.74 \mathrm{log}$ CFU/g) after submitting to boiling $(P<0.05)$. In the inoculated cooked sausages containing 55\% red meat, boiling and microwaving resulted in more retention of B. coagulans ATCC 31284 spores (8.78 and $8.75 \mathrm{log}$ $\mathrm{CFU} / \mathrm{g}$, respectively) compared with deep fat frying (8.68 $\log$ CFU/g), whereas the incorporated B. subtilis var. Natto ATCC 15245 spores had higher viability and recovery (8.95 log CFU/g) after submitting to boiling compared to the other home cooking methods examined $(P<0.05)$. The results also showed that the viable spore counts of B. coagulans ATCC 31284 inoculated into the cooked sausages with $70 \%$ red meat were significantly higher after submitting to boiling compared to the other studied household cooking methods. Besides, after household cooking through boiling and microwaving, B. subtilis var. Natto ATCC 15245 spores supplemented in the cooked sausages with $70 \%$ red meat showed the lowest losses (8.76 and $8.51 \log \mathrm{CFU} / \mathrm{g}$, respectively) $(P<0.05)$. Both probiotic strains of $B$. coagulans ATCC 31284 and B. subtilis var. Natto ATCC 15245 had the highest viability and recovery in the cooked sausages with $55 \%$ chicken after home cooking via boiling, followed by microwaving, and deep fat frying. In addition, enumeration of general (background) sporeformers in the control samples (with no incorporation of probiotic Bacillus spores) was insignificantly different in all home-cooked sausages except the cooked sausages with 55\% chicken, compared to the raw sample. The viable counts of the spores of probiotic Bacillus strains inoculated into the cooked sausage samples involving more than $40 \%$ meat were still above the minimum daily therapeutic dose of spore probiotics (i.e. $10^{6}$ CFU/g), regardless of home cooking methods. Fares et al. (37) also reported that cooking process caused a decline in the bacterial counts of B. coagulans GBI30,6086 that depended on the cooking time of the functional pasta, even though its amount in the cooked pasta (about $9.0 \log$ CFU/100 g) would be considered sufficient to exert beneficial effects on consumer.

Table 4. Effect of household cooking methods on the viable spore counts (log CFU/g) of B. coagulans ATCC 31284 and B. subtilis var. Natto ATCC 15245 supplemented in cooked sausages ${ }^{1}$

\begin{tabular}{|c|c|c|c|c|c|}
\hline \multirow[t]{2}{*}{ Sausage type ${ }^{2}$} & \multirow[t]{2}{*}{ Treatment $^{3}$} & \multicolumn{4}{|c|}{ Household cooking type ${ }^{4}$} \\
\hline & & RA & $\mathrm{BO}$ & MW & DFF \\
\hline \multirow{3}{*}{$40 \%$ red meat } & B. coagulans & $8.50 \pm 0.05^{\mathrm{A}}$ & $8.48 \pm 0.03^{\mathrm{A}}$ & $8.34 \pm 0.05^{\mathrm{A}}$ & $8.08 \pm 0.10^{\mathrm{B}}$ \\
\hline & B. subtilis & $8.75 \pm 0.05^{\mathrm{A}}$ & $8.74 \pm 0.02^{\mathrm{A}}$ & $7.92 \pm 0.03^{\mathrm{B}}$ & $7.63 \pm 0.02^{\mathrm{C}}$ \\
\hline & Control & $2.34 \pm 0.03^{\mathrm{A}}$ & $2.27 \pm 0.09^{\mathrm{A}}$ & $2.30 \pm 0.07^{\mathrm{A}}$ & $2.26 \pm 0.08^{\mathrm{A}}$ \\
\hline \multirow{3}{*}{$55 \%$ red meat } & B. coagulans & $8.85 \pm 0.08^{\mathrm{A}}$ & $8.78 \pm 0.02^{\mathrm{AB}}$ & $8.75 \pm 0.02^{\mathrm{AB}}$ & $8.68 \pm 0.06^{\mathrm{B}}$ \\
\hline & B. subtilis & $9.45 \pm 0.07^{\mathrm{A}}$ & $8.95 \pm 0.09^{\mathrm{B}}$ & $8.16 \pm 0.08^{C}$ & $8.03 \pm 0.09^{\mathrm{C}}$ \\
\hline & Control & $2.65 \pm 0.05^{\mathrm{A}}$ & $2.63 \pm 0.09^{\mathrm{A}}$ & $2.64 \pm 0.11^{\mathrm{A}}$ & $2.60 \pm 0.08^{\mathrm{A}}$ \\
\hline \multirow{3}{*}{$55 \%$ chicken meat } & B. coagulans & $9.43 \pm 0.05^{\mathrm{A}}$ & $9.11 \pm 0.04^{\mathrm{B}}$ & $8.95 \pm 0.05^{\mathrm{C}}$ & $8.76 \pm 0.05^{\mathrm{D}}$ \\
\hline & B. subtilis & $9.50 \pm 0.06^{\mathrm{A}}$ & $8.70 \pm 0.09^{\mathrm{B}}$ & $8.34 \pm 0.05^{\mathrm{C}}$ & $8.35 \pm 0.09^{C}$ \\
\hline & Control & $3.30 \pm 0.02^{\mathrm{A}}$ & $3.11 \pm 0.09^{\mathrm{B}}$ & $2.97 \pm 0.02^{\mathrm{B}}$ & $1.91 \pm 0.02^{\mathrm{C}}$ \\
\hline \multirow{3}{*}{$70 \%$ red meat } & B. coagulans & $8.77 \pm 0.06^{\mathrm{A}}$ & $8.63 \pm 0.04^{\mathrm{B}}$ & $8.40 \pm 0.06^{\mathrm{C}}$ & $8.44 \pm 0.07^{\mathrm{C}}$ \\
\hline & B. subtilis & $9.46 \pm 0.09^{\mathrm{A}}$ & $8.76 \pm 0.08^{\mathrm{B}}$ & $8.51 \pm 0.09^{\mathrm{B}}$ & $8.04 \pm 0.09^{\mathrm{C}}$ \\
\hline & Control & $2.65 \pm 0.05^{\mathrm{A}}$ & $2.64 \pm 0.09^{\mathrm{A}}$ & $2.63 \pm 0.10^{\mathrm{A}}$ & $2.60 \pm 0.08^{\mathrm{A}}$ \\
\hline \multicolumn{6}{|c|}{$\begin{array}{l}{ }^{1} \text { Each value represents the mean of two independent experiments }( \pm \mathrm{SD}) \text {. B. coagulans and B. subtilis spores were inoculated into the sausage batters at } 12.88 \\
\text { and } 12.96 \log \mathrm{CFU} / 10 \mathrm{Kg} \text {, respectively. Values were determined by plate count on trypticase soy agar after applying a heat shock at } 68^{\circ} \mathrm{C} \text { for } 20 \text { min. }\end{array}$} \\
\hline \multicolumn{6}{|c|}{${ }^{2}$ Sausages formulated with different types (red and chicken meats) and percentages $(40,55$, and $70 \%)$ of meat. } \\
\hline \multicolumn{6}{|c|}{$\begin{array}{l}\text { B. coagulans: sausage formulation containing B. coagulans ATCC } 31284 \text {; B. subtilis: sausage formulation containing B. subtilis var. Natto ATCC } 15245 \text {, } \\
\text { Control: production control without inoculation of probiotic sporeforming bacteria. }\end{array}$} \\
\hline \multicolumn{6}{|c|}{$\begin{array}{l}{ }^{4} \text { RA: raw; BO: boiling; MW: microwaving; DFF: deep fat frying. Boiling, microwaving and deep fat frying were done for } 5 \text { min at } 95 \pm 5^{\circ} \mathrm{C} \text {, for } 1 \text { min at the } \\
\text { highest power setting }(900 \mathrm{~W} \text {, at a frequency of } 2450 \mathrm{MHz}) \text {, and for } 3 \text { min at } 180 \pm 5^{\circ} \mathrm{C} \text {, respectively. Raw sample as a control was related to cooked sausages } \\
\text { on the } 15^{\text {th }} \text { day of refrigerated }\left(4 \pm 1^{\circ} \mathrm{C}\right) \text { storage. }\end{array}$} \\
\hline
\end{tabular}


The main effects for $\mathrm{S} / \mathrm{N}$ ratios of the three studied principal parameters at three levels are given in Table 5. As indicated, the type of spore probiotic (at levels 1 and 2; column 2) has the highest $\mathrm{S} / \mathrm{N}$ ratio, followed by the formulation of cooked sausages, and the method of household cooking of cooked sausages. It is also obvious from Fig. 1 that B. coagulans ATCC
31284 spores compared to B. subtilis var. Natto ATCC 15245 spores and sausage formulations with higher meat contents as well as boiling compared to other home cooking methods were more effective in obtaining the maximum viability and recovery of the studied probiotic sporeformers, respectively.

Table 5. S/N ratio at different levels of different parameters and delta values of the household cooking process

\begin{tabular}{cccc}
\hline Level & Sausage formulation & Spore probiotic & Household cooking method \\
\hline 1 & 14.54 & 18.65 & 15.27 \\
2 & 15.12 & 18.31 & 15.08 \\
3 & 15.26 & 7.96 & 14.57 \\
Delta $^{1}$ & 0.72 & 10.69 & 0.70 \\
Rank & 2 & 1 & 3 \\
\hline
\end{tabular}

${ }^{1}$ The difference of the values between the highest and lowest values of parameters, respectively.



Figure 1. $\mathrm{S} / \mathrm{N}$ ratios for main effects for all the three investigated parameters of the household cooking process.

\section{Disc ussion}

It is evident that several factors including meat sources in sausage manufacturing, presence and amount of different ingredients, especially those implicating spore germination and outgrowth, and time-temperature combinations of household cookings are all effective on the viability and recovery of probiotic Bacillus spores (38). Although moisture content is dominant, both ash and protein contents can affect thermal diffusivity and dielectric properties of cooked sausages (25). The results of the present study showed that except for final home cooking temperature, additional parameters such as the home cooking method (i.e. describes the rate of heat transfer to the interior of the sausages) may also affect the survival of probiotic Bacillus spores in cooked sausages. Furthermore, depending on the spore probiotic and sausage formulation, home cooking through boiling produced the lowest loss of the studied spores, while deep fat frying led to the greatest loss; in general, microwave occupied an intermediate position. It can be speculated that this higher viability in the number of CFU of the studied Bacillus spores in boiling could be related to remaining sausage casings and less thermal severity of this home cooking method compared to others. It is important to bear in mind that boiling will not give 
the sausages a crisp exterior; rather it will preserve the moisture and fat content within them. This makes boiling a good choice for home cooking of cooked sausage. Since the thermal conductivity and diffusivity of chicken meat are slightly higher than those of red meat (39), it is expected that the studied spores in the inoculated sausage samples and general (background) sporeformers in the control samples have been subjected to higher degrees of thermal energy, and thereby, greater unusual loss of probiotic and general sporeformers in the cooked chicken sausages (with 55\% chicken meat), compared to others. Besides, more thermal energy intake in the chicken sausage caused more denaturation of its muscular proteins; this, in turn, affected its water holding capacity and the protective effect of meat product on the viability and recovery of probiotic Bacillus spores $(40,41)$. Taguchi DOE (Design of Experiment) provides an opportunity to understand the main effects of factors, which are important for process analysis. Based on the results obtained by using this method, it can be concluded that the type of probiotic Bacillus spores, followed by the type of formulation of cooked sausages and the method of household cooking of cooked sausages, had significant influences on the response (viable spore counts of B. coagulans ATCC 31284 and B. subtilis var. Natto ATCC 15245), respectively (Table 5). It should be noted that there was a slight difference between the two types of probiotic Bacillus spores studied in terms of affecting the response (Fig. 1). The heat resistance of a spore can be related to two components: a) the intrinsic stability of the cellular components in vegetative cells, and b) the amount of additional stability achieved in the spore state (42). The facultative thermophilic status of $B$. coagulans makes it considerably more heat-resistant compared to Bacillus subtilis growing in the mesophilic temperature range (43). The results also revealed that the cooked sausages with higher meat contents (preferably $70 \%$ meat content) and home cooking by boiling had the greatest effect on the viability and recovery of the studied probiotic Bacillus strains, respectively. As mentioned before, to obtain a proper homogeneity of the studied Bacillus spores, they were incorporated at the beginning of cutterization (or chopping) process in the sausage manufacture. Therefore, meat as a main component in the cooked sausage batter caused the attachment (or adhesion) of the studied bacterial spores to it. It can be speculated that sausage formulations with higher meat contents resulted in more extraction of salt soluble meat proteins in the presence of added salt and phosphate. This, in turn, led to more stabilization of the studied spores within the cooked sausage batter.

\section{Conclusion}

The use of bacterial sporeformers as probiotics is a growing trend in the food market. The results of the study serve as a database providing information on the effects of different home cooking methods on the viability and recovery of probiotic Bacillus spores, and might encourage the food industry to recommend boiling as the cooking method of choice to help maintain the survivability of spore probiotics supplemented in cooked sausages. In addition, the results of this study indicated the ability of probiotic sporeformers for sustaining their life within various home cooking methods; properties that cannot be ensured with vegetative probiotic bacteria, confirming their capacity for usage, especially in functional cooked food products.

\section{Acknowledgement}

The authors would like to thank Gastroenterology and Liver Diseases Research Center, Research Institute for Gastroenterology and Liver Diseases, Shahid Beheshti University of Medical Science and Gooshtiran Factory of Meat Products, Tehran, Iran for their supports of this research.

\section{Financial disclosure}

The authors declare no financial conflicts of interest.

\section{Funding/Support}

The study did not receive any financial support.

\section{References}

1. Khan MI, Arshad MS, Anjum FM, Sameen A, Aneeq ur R, Gill WT. Meat as a functional food with special reference to probiotic sausages. Food Research International. 2011;44(10):3125-33.

2. Olmedilla-Alonso B, Jimenez-Colmenero F, SanchezMuniz FJ. Development and assessment of healthy properties of meat and meat products designed as functional foods. Meat Science. 2013;95(4):919-30.

3. Turp GY. Effects of four different cooking methods on some quality characteristics of low fat Inegol meatball enriched with flaxseed flour. Meat Science. 2016;121:40-6.

4. FAO/WHO. Guidelines for the evaluation of probiotics in food. London Ontario, Canada: Food and Agriculture 
Organization of the United Nations and World Health Organization Working Group Report, 2002.

5. Venema K, do Carmo AP. Probiotics and prebiotics: current research and future trends. In: Venema K, do Carmo AP, editors. Probiotics and prebiotics: current research and future trends. Norfolk, UK: Caister Academic Press; 2015. p. 3-12.

6. Cutting SM. Bacillus probiotics. Food Microbiology. 2011;28(2):214-20.

7. Endres JR, Clewell A, Jade KA, Farber T, Hauswirth J, Schauss AG. Safety assessment of a proprietary preparation of a novel Probiotic, Bacillus coagulans, as a food ingredient. Food and Chemical Toxicology. 2009;47(6):1231-8.

8. Ashraf R, Shah NP. Selective and differential enumerations of Lactobacillus delbrueckii subsp. bulgaricus, Streptococcus thermophilus, Lactobacillus acidophilus, Lactobacillus casei and Bifidobacterium spp. in yoghurt: a review. International Journal of Food Microbiology. 2011;149(3):194-208.

9. Jayamanne VS, Adams MR. Determination of survival, identity and stress resistance of probiotic Bifidobacteria in bio-yoghurts. Letters in Applied Microbiology. 2006;42(3):189-94

10. Spinosa MR, Braccini T, Ricca E, De Felice M, Morelli L, Pozzi G, et al. On the fate of ingested Bacillus spores. Research in Microbiology. 2000;151(5):361-8.

11. Patel AK, Ahire JJ, Pawar SP, Chaudhari BL, Chincholkar SB. Comparative accounts of probiotic characteristics of Bacillus spp. isolated from food wastes. Food Research International. 2009;42(4):50510.

12. Katsutoshi A, Shinichi M, Tadasi H, Ichirou T, Kazuya $\mathrm{O}$, Shuji K, et al. Effect of spore-bearing lactic acidforming bacteria (Bacillus coagulans SANK 70258) administration on the intestinal environment, defecation frequency, fecal characteristics and dermal characteristics in humans and rats. Microbial Ecology in Health and Disease. 2011;14(1):4-13.

13. Urdaci MC, Bressollier P, Pinchuk I. Bacillus clausii probiotic strains: antimicrobial and immunomodulatory activities. Journal of Clinical Gastroenterology. 2004;38(6 Suppl):S86-90.

14. Nithya V, Halami P. Evaluation of the probiotic characteristics of Bacillus species isolated from different food sources. Annals of Microbiology. 2013;63(1):129-37.

15. Bezkorovainy A. Probiotics: determinants of survival and growth in the gut. The American Journal of Clinical Nutrition. 2001;73(2 Suppl):399s-405s.

16. Shah NP. Functional foods from probiotics and prebiotics. Food Technology. 2001;55:46-53.

17. Bader J, Albin A, Stahl U. Spore-forming bacteria and their utilisation as probiotics. Beneficial Microbes. 2012;3(1):67-75.
18. Gallego CG, Salminen S. Novel probiotics and prebiotics: how can they help in human gut microbiota dysbiosis? Applied Food Biotechnology. 2016;3(2):7281.

19. Postollec F, Mathot AG, Bernard M, Divanac'h ML, Pavan S, Sohier D. Tracking spore-forming bacteria in food: from natural biodiversity to selection by processes. International Journal of Food Microbiology. 2012;158(1):1-8.

20. Turnbull PC, Frawley DA, Bull RL. Heat activation/shock temperatures for Bacillus anthracis spores and the issue of spore plate counts versus true numbers of spores. Journal of Microbiological Methods. 2007;68(2):353-7.

21. Jafari M, Alebouyeh M, Mortazavian AM, Hosseini H, Ghanati K, Amiri Z, et al. Influence of heat shock temperatures and fast freezing on viability of probiotic sporeformers and the issue of spore plate count versus true numbers. Nutrition and Food Sciences Research. 2016;3(1):35-42.

22. Wells-Bennik MH, Eijlander RT, den Besten HM, Berendsen EM, Warda AK, Krawczyk AO, et al. Bacterial spores in food: Survival, emergence, and outgrowth. Annual Review of Food Science and Technology. 2016;7:457-82.

23. Smelt JPPM, Bos AP, Kort R, Brul S. Modelling the effect of sub(lethal) heat treatment of Bacillus subtilis spores on germination rate and outgrowth to exponentially growing vegetative cells. International Journal of Food Microbiology. 2008;128(1):34-40.

24. Manios SG, Skandamis PN. Effect of frozen storage, different thawing methods and cooking processes on the survival of Salmonella spp. and Escherichia coli O157:H7 in commercially shaped beef patties. Meat Science. 2015;101:25-32.

25. Zheng M, Huang YW, Nelson SO, Bartley PG, Gates KW. Dielectric properties and thermal conductivity of marinated shrimp and channel catfish. Journal of Food Science. 1998;63(4):668-72.

26. Venkatesh MS, Raghavan GSV. An overview of microwave processing and dielectric properties of agrifood materials. Biosystems Engineering. 2004;88(1):118.

27. Castorena-Cortes G, Roldan-Carrillo T, Zapata-Penasco I, Reyes-Avila J, Quej-Ake L, Marin-Cruz J, et al. Microcosm assays and Taguchi experimental design for treatment of oil sludge containing high concentration of hydrocarbons. Bioresource Technology. 2009;100(23): 5671-7.

28. Das Mohapatra PK, Maity C, Rao RS, Pati BR, Mondal KC. Tannase production by Bacillus licheniformis KBR6: Optimization of submerged culture conditions by Taguchi DOE methodology. Food Research International. 2009;42(4):430-5.

29. Dimou M, Marnasidis S, Antoniadou I, Pliatsika M, Besseris GJ. The application of Taguchi method to 
determine the optimum blend of unifloral honeys to most closely match thyme honey quality. International Journal of Food Science \& Technology. 2009;44(10):1877-86.

30. Bhat AR, Irorere VU, Bartlett T, Hill D, Kedia G, Morris MR, et al. Bacillus subtilis natto: a non-toxic source of poly-gamma-glutamic acid that could be used as a cryoprotectant for probiotic bacteria. AMB Express. 2013;3(1):36.

31. Azimirad M, Alebouyeh M, Naji T. Inhibition of Lipopolysaccharide-Induced Interleukin 8 in Human Adenocarcinoma Cell Line HT-29 by Spore Probiotics: B. coagulans and B. subtilis (natto). Probiotics and Antimicrobial Proteins. 2016;8:1-8.

32. Alebouyeh M, Behzadian-Nejad Q, Soleimani M, Hassan Z, Salmanian A, Zali MR. Characterization of the interaction of undomesticated Bacillus subtilis spores with Caco-2 cell line. Annals of Microbiology. 2009;59(2):273-7.

33. ISO. Meat and meat products -sampling and preparation of test samples - Part 1: Sampling, 3100-1. International Standard Organization; 1991.

34. Taguchi G. Introduction to quality engineering: designing quality into products and processes. Tokyo: Asian Productivity Organization; 1986. 191 p.

35. Sasmal S, Goud VV, Mohanty K. Optimisation of the acid catalysed pretreatment of areca nut husk fibre using the Taguchi design method. Biosystems Engineering. 2011;110:465-72.

36. Nunes CA, Alvarenga VO, de Souza Sant'Ana A, Santos JS, Granato D. The use of statistical software in food science and technology: Advantages, limitations and misuses. Food Research International. 2015;75:270-80.

37. Fares C, Menga V, Martina A, Pellegrini N, Scazzina F, Torriani S. Nutritional profile and cooking quality of a new functional pasta naturally enriched in phenolic acids, added with b-glucan and Bacillus coagulans GBI-30, 6086. Journal of Cereal Science. 2015;65:26066.

38. Bejerholm C, Aaslyng MD. The influence of cooking technique and core temperature on results of a sensory analysis of pork depending on the raw meat quality. Food Quality and Preference. 2004;15(1):19-30.

39. Huang L, Liu L-S. Simultaneous determination of thermal conductivity and thermal diffusivity of food and agricultural materials using a transient plane-source method. Journal of Food Engineering. 2009;95:179-85.

40. Pan Z, Singh RP. Physical and thermal properties of ground beef during cooking. Food Science and Technology 2001;34:437-44.

41. Marcotte M, Tahérian AR, Karimi-Zindashty Y. Thermophysical properties of processed meat and poultry products. Journal of Food Engineering. 2008;88(8):315-22.

42. Warth AD. Relationship between the heat resistance of spores and the optimum and maximum growth temperatures of Bacillus species. Journal of Bacteriology. 1978;134(3):699-705.

43. Vos P, Garrity G, Jones D, Krieg NR, Ludwig W, Rainey FA, et al. Bergey's manual of systematic bacteriology. New Delhi, India: Springer-Verlag New York; 2009. 1450 p. 